\title{
Н.Б. Афанасов* \\ К ВИЗУАЛЬНОЙ СЕМИОТИКЕ ФАШИСТСКОЙ УТОПИИ: «ЗВЕЗДНЫЙ ДЕСАНТ» ПОЛА ВЕРХОВЕНА
}

Статья предлагает анализ идеологических нарративов в культовом фильме Пола Верховена «Звездный десант» (1997). Нидерландско-американский автор известен своим особенным и провокационным подходом к режиссуре, который объединяет низкое и высокое. Помимо прочего, Пол Верховен предлагает в своих фильмах высказывания о таких философских категориях, как власть, насилие, утопия, сексуальность и др. «Звездный десант» является одним из самых противоречивых произведений режиссера, представляя собой экзотерическую критику фашистской утопии. Автор статьи указывает, что разночтения в интерпретациях, которые можно обнаружить в исследовательской литературе, заслуживают отдельного анализа. Прибегая к методологической рамке визуальной семиотики, а также обращаясь к литературному прототипу фильма, одноименному роману Роберта Хайнлайна, статья показывает, что в плане критического высказывания фильм вышел за границы замысла режиссера. В конечном итоге прямая интерпретация фильма как апологетики насилия и шовинизма имеет свою реальную основу, что порождает ряд вопросов о нейтральности роли первоисточника, сценаристов и самой избранной Верховеном визуальности.

Ключевые слова: утопия, социальная философия, анализ фильма, философия кино, фашизм, национал-социализм, Пол Верховен, «Звездный десант»

Towards visual semiotics of fascist utopia: Paul Verhoeven's «Starship troopers». NIKOLAI B. AFANASOV (Institute of Philosophy, Russian Academy of Sciences)

The article offers an analysis of ideological narratives in Paul Verhoeven's cult film «Starship troopers» (1997). The Dutch-American author is known for his special and provocative approach to directing, which combines the low-brow with the high-brow. Among other things, in his films Paul Verhoeven offers statements about such philosophical categories as power, violence, utopia, sexuality, etc. «Starship troopers» is one of his most controversial works, representing an exoteric criticism of the fascist utopia. The author of the article points out that discrepancies in interpretations of the film, which can be found in the research literature, are worth analyzing. Using the methodological framework of visual semiotics and referring to the literary prototype of the film, Robert Heinlein's novel of the same name, the article shows that in terms of critical expression the film went beyond the boundaries of the director's plan. In the end, the direct interpretation of the film as apologetics for violence and chauvinism has its own real basis, which raises a number of questions about the neutrality of the role of the original source, the screenwriters' work, and the visual style chosen by Verhoeven.

Keywords: utopia, social philosophy, film analyses, philosophy of cinema, fascism, national socialism, Paul Verhoeven, «Starship troopers»

* АФАНАСОВ Николай Борисович, младший научный сотрудник сектора социальной философии Института философии РАН.

E-mail: n.afanasov@gmail.com

(C) Афанасов Н.Б., 2020 
Авторское кино всегда находилось в фокусе внимания философов. Но массовый кинематограф стал предметом исследования сравнительно недавно. Несколько десятилетий назад область философии кино стала вытесняться новой дисциплиной - cinema studies. Этот процесс маркирует переход от анализа авторского и/или фестивального кино к работе с массовыми продуктами. Подходы к пониманию феноменов, тем не менее, значительно различаются как по используемым методам, так и по своим задачам. Особенную сложность представляет работа с произведениями режиссеров, которые начинали как «авторы», но впоследствии стали снимать массовое кино. Кинематограф можно анализировать формально, как часть визуального извода культуры, включенной в общий контекст символического производства. Но можно анализировать его и как специфическое высказывание, обладающее нередуцируемым к форме содержанием. Кинопроизводство, особенно распространившееся после Второй мировой войны и заслуженно ставшее явлением, претендующим на культурную гегемонию [3, с. 198], предложило универсальный язык изображения взамен национальным языкам и замкнутым культурным кодам. Визуальность в самой своей задаче стремится к их преодолению [2, с. 50-51]. В таком понимании кинематограф, казалось бы, не требует работы «переводчика».

Однако кажущееся языковое упрощение способа передачи информации, имеющее своей целью главным образом расширить потребительскую аудиторию, не всегда подразумевает примитивизацию смысла высказывания. Более того, по историческим меркам фильм как способ репрезентации смыслов сравнительно нов, и не следует поддаваться соблазну достаточности использования привычного нам арсенала герменевтической традиции для его полноценного понимания [14, p. 225]. Ситуация вдобавок осложняется тем, что не все кино авторское, и становится еще более запутанной, если «автор» снимает массовое кино. Это происходит потому, что формат серьезной работы с массовой культурой предполагает рефлексивный исследовательский подход и мастерское владение материалом массовой же культуры, чем могут похвастаться немногие [6, с. 20-21]. «Переводчик» фильму все еще не нужен, но вот без интерпретатора сложность смысла может ускользнуть даже от весьма искушенного зрителя.
Порой происходит странное - в произведении оказывается больше содержания, чем хотел сказать автор. Бывает и так, что само содержание начинает жить своей, отличной от замысла автора жизнью.

Научно-фантастический фильм «Звездный десант» Пола Верховена 1997 г. в момент выхода в прокат бросил вызов и интерпретаторам, и аудитории. Высокобюджетному голливудскому научно-фантастическому боевику, снятому нидерландским по происхождению режиссером с именем и сложившейся репутацией артхаусного автора, предшествовали невероятно коммерчески успешный, получивший статус культового фильм «Вспомнить все» (1990) и потерпевший полный провал несмотря на широкую рекламную кампанию [8, с. 80-81], завоевавший анти-премию «Золотая малина» стрип-мюзикл «Шоугелз» (1996). Между этими двумя фильмами в 1992 г. Верховен снял еще один важный для истории кинематографа фильм - скандальный и успешный «Основной инстинкт». Со «Звездным десантом» произошло что-то среднее между этими тремя примерами: фильм не был успешен в прокате, но и не провалился. Статус общепризнанного «культового кино», как и многие другие фильмы Верховена, он приобрел, но лишь спустя годы [9, р. 35-36].

Такая неочевидная судьба фильма как раз и была связана со сложностями восприятия, которые имеют важное значение в производстве фильма как завершенного феномена (сам фильм всегда представляет собой результат работы и создателей, и зрителей) [4, с. 45-47]. Критика отнеслась к картине негативно, в результате определенного считывания того социально-политического высказывания, которое вкладывал в картину режиссер. Как отмечает сам Верховен, многие даже не поняли ироничности картины [12, р. 130]. И это, несомненно, повлияло на коммерческую судьбу «Звездного десанта». Ирония, пародийность и гротеск, присущие творчеству и специфическому киноязыку Верховена [25, р. 296], в фильме главным образом выражены через визуальные символы, отсылающие к ряду контекстов, чаще всего - но не только - ассоциирующихся с фашизмом и национал-социализмом [11]. Без считывания этих знаков и их соотнесения с тем визуальным цитированием, к которому прибегает режиссер, история главного героя Джона Рико была бы обычной историей простого и патриотичного выпускника школы, выходца из семьи, принад- 
лежащей к высшему среднему классу, который вступает в армию из-за девушки и под влиянием любимого учителя. Эту историю, учитывая бюджет фильма и репутацию режиссера, ждал бы безоговорочный успех, и, предположим, ряд незначительных претензий и упреков со стороны критиков в банальности сюжета.

В нашем рассмотрении «Звездного десанта» мы обратимся не только к очевидным киноцитированиям, в значительном количестве присутствующим на экране, но и к жанровой структуре фильма, содержащей то, что мы называем «структурным» цитированием, отсылающим к зрительскому опыту других культурных продуктов и создающим восприятие фильма в процессе его просмотра определенной аудиторией $[4$, c. 56]. Структурность цитирования особенно важна для понимания замысла автора, создающего продукт массовой культуры, поскольку цитата, включенная в киноповествование, не только имеет референтом оригинал, но и находится в сложной системе смысловых взаимоотношений с другими отсылками в ткани фильма. Говоря о сопутствующем толкованию произведения контексте, отметим, что дополнительная сложность может возникнуть, если учесть, что «Звездный десант» Пола Верховена имеет прототип - одноименный роман Роберта Хайнлайна 1959 г. Как и фильм, книга была неоднозначно встречена публикой, не сразу вошла в традиционный канон мейнстримной фантастики 1950-х и 1960-х гг. и ставила перед читателем ряд провокационных вопросов [13; 23]. В конечном счете книга приобрела культовый статус. Однако история создания фильма не соответствует критериям, позволявшим бы с полной уверенностью отнести ее к «экранизациям». Эдвард Ноймайер, участвовавший в работе над рядом других фильмов Верховена, таких как «Робокоп» и «Вспомнить все», изначально писал сценарий под рабочим названием «Охота на жуков на аванпосте №9», не связанным с романом Хайнлайна. Вопросы авторского права, перекличка основных тем и популярность первоисточника привели к решению изменить название и ориентироваться при создании фильма в том числе и на книгу. Впрочем, лишь до определенной степени, поскольку попытка самого Верховена ознакомиться с произведением не увенчалась успехом: «Я остановился спустя две главы, потому что это было так скучно... Это действительно довольно плохая книга. Я попросил Эда Ноймайера рассказать мне сюжет, потому что я просто не мог ее прочесть. Это очень правая книга» [26, p. 189].

Мы начнем обзор репрезентаций и кросскультурных отсылок в фильме с бросающегося в глаза провокативного визуального киноцитирования, к которому сознательно прибегает Верховен. Оно усиливается не только тем, что в «Звездном десанте» достаточно отсылок к символике исторического нацизма, но и более общим контекстом цитирования. Впрочем, того количества обращений к эстетике национал-социализма, которое есть в фильме, было бы уже достаточно для того, чтобы вызвать чувство морального дискомфорта у посетителя кинотеатра, который пришел развлечься и почувствовать солидарность с героями, борющимися за правое дело. Ведь рядовой кинозритель, на что рассчитывает Верховен, нагружен знанием о массовой культуре, в изобилии предоставляющий изображения из эпохи Второй мировой войны [20]. Зритель также - как потребитель идеологии - всегда знает, какую оценку нужно выносить тому или иному явлению.

Более всего впечатлившим публику и критику в фильме является визуальное обращение к пропагандистской картине Лени Рифеншталь «Триумф воли» (1935), очевидность и важность которой для структуры «Звездного десанта» позволяет ряду исследователей говорить о сознательно предпринятой «мимикрии» под национал-социалистический пропагандистский фильм [11, p. 104]. Задача этой мимикрии не сводится к сатире и пародии, но служит появлению эмпатии, идентификации с происходящим на экране: «Помните кадры в начале "Звездного десанта", где они все поворачиваются к камере и говорят: “Я исполняю свой долг!”? Это прямо из фильма Лени, где один парень разворачивается и говорит: “Я из Силезии”. А затем другой говорит: “Я из Баварии”» [12, p. 132]. Пропаганда обращается прямо к зрителю, к нам. При этом следует отметить «идеальную» внешность героев, чья кожа лишена изъянов и сильно отретуширована в кадре, что также сознательно отсылало к эстетике нацистской пропаганды, предпочитавшей использовать изображения красивых героев [12, p. 132].

Главный смысл провокации, однако, не просто в обращении к нацисткой пропагандистской кинопродукции, но в помещении ее в определенный контекст: вторым наиболее важным визуальным ориентиром «Звездного десанта» выступает американский пропагандистский 
многосерийный фильм времен Второй мировой «Почему мы сражаемся» (1942-1945), созданный по заказу правительства Фрэнком Капрой и Анатолем Литваком для оправдания участия американских военных в кампании на континенте. Полом Верховеном создается смысловое напряжение, когда в один ряд ставится немецкий нацизм и американский патриотизм, хотя последний, казалось бы, должен представляться правильной и положительной позицией по меньшей мере для целевой аудитории фильма: «Риторика гражданственности и долга, видео "Почему мы сражаемся", отсылающее к знаменитой серии Фрэнка Капра времен Второй мировой, транслируемые изображения резни, шутливая сцена “внутреннего фронта", в которой дети радостно давят жуков, - все эти элементы предлагают верную и даже необходимую стратегию действия» [22, p. 33].

Герои фильма, на первый взгляд, действительно являются положительными персонажами, ничем не отличающимися от привычных образов, тиражируемых боевиками [15, р. 128], и сражаются за будущее Земли. Но они сражаются, являясь гражданами Земной Федерации, герб которой отсылает к «государственному орлу» нацистской Германии. За образец их серых оттенков военной формы была взята форма различных подразделений Вермахта с соблюдением деления на рода войск, что заметно на примере костюмов офицеров космофлота, практически идентичных форме «Люфтваффе». Еще более показательно это сходство проявляется в кожаных плащах интеллектуальной элиты армии, куда попадает из-за своих выдающихся аналитических и психических способностей друг Джона Рико Карл. Их обмундирование полностью копирует плащи членов отрядов SS. Режиссер сознательно подбирал на главные роли героев с лицами, отсылающими к персонажам нацистских роликов [12, р. 132].

Обратим внимание, что в фильме имеет место зависимость идентичности образцов формы от интеллектуальных требований для попадания в определенный род войск: Кармен Ибанес, девушка главного героя на момент начала фильма, талантливее Рико в математике и поэтому попадает в космофлот; Карл Дженкинс, лучший друг Рико, обладая фактически экстрасенсорными способностями, оказывается в военной разведке, где быстро делает карьеру и спустя некоторое время руководит бывшими товарищами по школе. Их форма куда больше походит на нацистскую, чем форма Рико, который, не обладая особыми интеллектуальными способностями, попадает в межгалактические десантные войска. Обстановка же в казарме десантников практически не отсылает к нацизму, а воспроизводит стандартные изображения быта американских военных, тем самым, во-первых, укрепляя ощущение идентификации зрителя с простыми солдатами, а, во-вторых, играя с представлениями массового зрителя о стиле элиты нацистских вооруженных сил [16, p. 312-314].

Все эти отсылки подаются как нечто естественное, вписанное в логику повествования, не становясь предметом метакритического, ироничного высказывания, о котором говорит режиссер в многочисленных интервью [12]. Реальность вселенной «Звездного десанта» совпадает с нашей: нам предлагается взглянуть на мир не столь далекого будущего. Эта реальность помнит о своей и нашей истории, правда, совершенно особенным образом. В частности, во время школьного урока преподаватель истории и философии Расчек, являющийся чрезвычайно важным персонажем для повествования, выдвигает контраргумент на высказывание одной из учениц о том, что насилие ничего не решает: он предлагает вспомнить Хиросиму. Без каких-либо уточнений со стороны преподавателя по реакции аудитории видно, что аргумент сработал. То есть события Второй мировой войны, а также, предположим, ее визуальность не были утрачены в исторической памяти и до сих пор понятны старшеклассникам. Видимо, в данном случае речь идет об «избирательности»: люди помнят о ядерной бомбардировке японских городов, но не осознают, что вооруженные силы их государства сражаются в нацистской форме.

Сцены из первой части фильма, где мы наблюдаем будущих солдат, сидящих на уроках, играющих в американский футбол, танцующих на выпускном бале, сообщают нам много об истории и социально-политической организации изображаемого общества. Присутствуя на двух уроках - экзобиологии, а также совмещенных истории и философии, мы узнаем, что некогда демократия привела общество к хаосу, но ветераны сумели разрешить кризис, взяв власть в свои руки. Эдвард Ноймайер, более внимательно работавший с текстом романа Хайнлайна и многое вложивший в фильм в идейном отношении, определяет его тематику как связанную с проблемами демократическо- 
го устройства, не имеющего иммунитета к фашизму, скрытому в человеческой природе: «У меня было ощущение, что сегодняшняя киноаудитория оценит идеи Хайнлайна. Потому что посыл оригинальной книги был довольно прямолинеен: демократия терпит крах, и нам необходим строгий контроль над нашей культурой» [18, p. 10].

Учитывая, что режиссер также знакомит нас с органами верховной власти Земной Федерации, которые показывают в новостных сводках, интерпретация «власти ветеранов» должна быть понята как вариация «культурной гегемонии», предполагающей ангажированность учителя, выступающего по отношению к транслируемой им молодому поколению культуре в качестве скульптора и философа [1, с. 433-442]. Возможно, что в прошлом ветераны управляли Федерацией напрямую, но сейчас многие из них, продолжая задавать общий культурный тон, ушли с руководящих постов. Заметно, что среди политиков и управленцев есть много молодых людей, но вот среди преподавателей мы видим только двух людей среднего или даже старшего возраста, имеющих увечья, которые были получены на войне - у Расчека нет одной руки, а лицо преподавателя экзобиологии обожжено, она незряча. В конечном счете именно Расчек, как преподаватель философии и как философ, оказывает решающее влияние на принятие Рико решения о вступлении в ряды вооруженных сил.

Расчек делает это, в сущности, достаточно изящно, прибегая к сократическому методу, то есть задавая оппоненту вопросы. Основной внутренний конфликт главного героя разворачивается вокруг проблемы политического участия и инициированного этим кризиса самоидентификации $[15$, p. 126]. В обществе Земной Федерации существует жесткое разделение на две неравные в правах группы: гражданских и граждан. Это «неравенство» не накладывает отпечатка на уровень материального благополучия. Родители Рико - «гражданские», но имеют прекрасный дом, работу и, кажется, ни в чем не ограничены. Поэтому они выступают против идеи сына стать гражданином, ведь для них потенциальные приобретения непропорциональны издержкам. Для получения более высокого статуса необходимо прохождение непростой воинской службы. В числе будущих преференций - возможность участия в политическом процессе и лицензия на рождение ребенка. Отличие от подлинно философского вопрошания Сократа в том, что учитель Расчек всегда знает правильные ответы и дает моральную оценку «неправильным». Вдобавок он, естественно, находится во властной позиции по отношению к ученикам. В фильме есть и визуальное обращение к философии. На стенде в классе висят репродукция платоновской пещеры, гравюра бюста Аристотеля и портрет, вероятно, наиболее важного для фильма философа - Фридриха Ницше.

Об идеологическом устройстве и ценностях ветеранов, которые транслируют последние в школе, мы узнаем на уроке экзобиологии. Преподаватель, рассказывая о социальном устройстве арахнидов, за препарацией одного из представителей внеземной расы, обращает внимание на их совершенство. Не обладая, как отмечает биолог, индивидуальностью и ложными потребностями, арахниды становятся идеальными солдатами. Их выживаемость и устойчивость к внешним воздействиям также значительно превосходят человеческие ресурсы. Строго иерархичная политическая система жуков делает возможной быструю и эффективную военную мобилизацию. Поэтому в неизбежном столкновении человечества и арахнидов за «жизненное пространство» [11, p. 105] речь будет идти о социал-дарвинистской борьбе видов или, если угодно, рас за выживание. Это не преувеличение, поскольку герои фильма никогда не говорят об отражении агрессии или конфликте ограниченного масштаба. Один из пилотов космофлота перед смертью бросает такую фразу: «Придет час, и такой же человек, как я, уничтожит тебя и всех вас, тварей!» ${ }^{1}$.

Важной частью «структурного» цитирования фильма, не являющейся отсылкой к видеопродукции широко известных аудитории исторических источников, можно назвать его интерактивный дизайн, заигрывавший с только набиравшим популярность интернетом и его форматом подачи новостей: «“Звездный десант” (1997) предлагает разнообразие пропаганды, новостей и коммерческих клипов, представленных как часть всемирного интерактивного видеосигнала, который отсыла-

${ }^{1}$ В цитате приведен официальный русский дубляж, который из цензурных соображений недостаточно передает расистские коннотации. В оригинале фраза звучит так: «One day someone like me is going to kill you and your whole fucking race! (курсив мой. прим. авт.)». 
ет к работе интернета» [14, р. 4]. Новостные сводки, с которыми нас знакомит режиссер, выстроены по принципу участия смотрящего, предлагая тому включиться в активный процесс ознакомления с происходящим, выбирая на экране из нескольких опций, а также кликая курсором мышки надпись «Вы хотите знать больше?», стилизованную под отображение интернет-страниц в ранних версиях браузера Internet Explorer. Обращение к функционированию интернет-культуры на момент выхода в прокат работало на снижение градуса иронического восприятия фильма, мимикрируя под медиа-реальность настоящего.

Выбор этого смешения форм пропагандистского ролика, новостного выпуска и полноценного фильма в единственном моменте предоставляет возможность сломать «четвертую стену», обратившись к реальности разума, а не эмоциям, владеющим нами и героями повествования при виде сцен смертей. Репортер, ведущий трансляцию из казармы, дает вводку, которая должна была бы пробудить у зрителей новостной программы, уже кликнувших на «Вы хотите знать больше?», и, соответственно, у зрителей фильма сомнения в оправданности происходящей кровавой бани: «Некоторые говорят, что жуки были спровоцированы вторжением в среду их естественного обитания, что политика “жить и давать жить другим" могла бы быть предпочтительнее войны...». Мысль, которая на самом деле звучала в фильме ранее, о том, что агрессия жуков является ответной реакцией на вторжение колонистов, прерывается Рико: «Я из Буэнос-Айреса, и я говорю: "Убить их всех!"».

Отдельная тема фильма - это репрезентация последствий насилия, показанных чрезвычайно реалистично и физиологично: пустые черепные коробки с высосанными жуками мозгами, оторванные конечности, вываливающиеся кишки. Изображая поле боя, Пол Верховен не жалеет зрителя. Жестокость и насилие повсеместны как в отношении людей, так и в отношении арахнидов, которых также безжалостно убивают и над которыми ставят эксперименты жители Земли. Сам режиссер в одном из интервью о насилии заявил: «Я не знаю, как обойти тему, если мир стал бойней» [15, р. 129]. Визуальное рассмотрение изображений жестокости и насилия в фильме могло бы стать темой для отдельного исследования, однако для нас в первую очередь важна взаимная структура на- силия: и жуки, и люди в своей агрессии поступают симметрично.

То, что у жуков якобы отсутствуют чувства, заблуждение. В нескольких моментах фильма мы видим глаза арахнидов перед смертью, и в них нет ничего кроме страха и боли. Для того, чтобы это не осталось незамеченным зрителем, в конце повествования, когда военной разведке удается захватить одного из главных жуков-интеллектуалов, тем самым приблизив человечество к победе в межвидовом и межрасовом конфликте, Карл, напомним, обладающий чем-то вроде телепатии, говорит о жуке: «Он боится!»

В рамках темы насилия также есть один любопытный пример «структурного» цитирования. В одном из эпизодов новостного выпуска в фильме для подтверждения опасности арахнида транслируются кадры того, как он, находясь в клетке, убивает специально приведенную туда корову, что является отсылкой к популярному в 1950-х и 1960-х гг. тропу научно-фантастических фильмов про пришельцев [7].

Но причем здесь утопия? Если с «фашизмом» в фильме все ясно, то, взяв за скобки эстетику нацизма, давайте обратимся к той реальности, которую изображает фильм. Герои счастливы, несмотря на все, что происходит вокруг них. Ни смерть родных, ни смерть друзей, ни что бы то ни было не может вызвать у них продолжительную негативную эмоцию или заставить их задавать вопросы о происходящем. Даже собственная возможная смерть не становится отправной точкой экзистенциального переживания. Она заглушается риторическим вопросом Расчека: «Вы что, хотите жить вечно?» Чувство единения и ощущения от выполняемого правого общего дела, предоставляемые государством, снимают все вопросы. Личностное измерение жизни, которое могло бы стать источником проблем, всегда разрешается через структуры власти либо при моральной поддержке ветеранов. Это хорошо описывается метафорой, сопровождающей завершение школьного бала и части фильма, не посвященной войне, до которого многие из героев находятся в кризисе: танцпол растворяется в орле герба Земной Федерации.

Социальные структуры также утопичны и не всегда редуцируются к влиянию утопического мышления национал-социализма. В частности, фильм заигрывает с темами гендерного равенства и политкорректности. Знаменитой стала сцена, в которой солдаты - и мужчины, и женщины - принимают душ вместе. Несмотря на 
традиционно присущее изображениям фашизма в массовой культуре превознесение маскулинности [19, р. 141], Верховен сознательно подчеркивает равные возможности и де факто равное положение между женщинами и мужчинами в обществе. Помимо высказывания о гендерной проблеме, Верховен включает в повествование и темнокожих актеров, а родным городом героев является латиноамериканский Буэнос-Айрес. Расового конфликта между жителями Земной Федерации нет. Идеалы американского равенства, в сущности, реализованы во вселенной «Звездного десанта». Впрочем, необходимо отметить одну любопытную деталь: «Вероятно неслучайно, что фильм не изображает азиатских персонажей, поскольку их культурная инаковость была включена в практически непроницаемые тела инопланетных насекомых» $[10$, р. 51-52].

Ранее высказанные нами наблюдения не должны приводить читателя и зрителя к поспешной интерпретации фильма как просто ироничной подмены семейного фильма про войну на пропаганду милитаризма. Безусловно, Верховен изначально обманывал свою аудиторию и снял не простой научно-фантастический боевик. Однако подмена сложнее, и абсолютно неправильно думать, что увидеть за красочной картинкой скрытый фашизм означает понять фильм. Наиболее любопытным и наименее исследованным в литературе является жанровое своеобразие фильма, также являющееся «структурным» цитированием. Это понимание фильма как традиционной молодежной комедии с элементами эротики ${ }^{2}$. В повествовании присутствуют все основные сцены, сопутствующие фильмам об американской школе, с поправкой на то, что события происходят в будущем: препарирование арахнида (ср. с лягушкой), спортивный матч, домашняя работа, выпускной бал. Связь секса и фашизма традиционно интерпретируется как укорененная в садомазохистских, нетрадиционных отношениях, наиболее известным кинематографическим воплощением чего служит фильм Лилианы Кавани «Ночной портье» (1974)

\footnotetext{
2 Как ни странно, в академических публикациях это измерение фильма фактически не отражено, однако команда YouTube-канала «Wisecrack», созданного группой американских философов и киноведов, выпустила аналитический разбор «Звездного десанта» под названием «Starship troopers: how to make fascism SEXY», где в том числе затрагивается и обсуждаемая нами тема (см.: [21]).
}

[17]. Но в «Звездном десанте» нет ничего нетрадиционного, и важно именно это.

Нельзя останавливаться на удобной и психологически комфортной интерпретации «Звездного десанта» как слишком тонкой сатиры, непонятой критиками сразу, но понятой впоследствии нами. Дело в том, что критики ошиблись не потому, что хотели ошибиться, и даже не потому, что были недостаточно компетентны для работы с фильмом Верховена. Пол Верховен, пусть он сам и определяет главной задачей своего фильма критику внешнеполитического империализма США [12, р. 137], ставит вопросы о смысле и границах демократии, политического участия, патриотизма, утопизма. На это, в частности, обращает внимание философ Виталий Куренной, указывая в контексте фильма, «насколько смысл человеческого существования пропитан политическими категориями» $[5$, с. 131]. И именно визуальное, которое мимикрирует не только под фашизм, но и под традиционное голливудское кино, дает нам понять эту серьезность и не отбрасывать сразу смысл «прямой» интерпретации «Звездного десанта».

\section{СПИСОК ЛИТЕРАТУРЫ}

1. Грамши А. Тюремные тетради: в 3-х ч. Ч. 1. М.: Политиздат, 1991.

2. Гройс Б. Квентин Мейясу - это в чистом виде Сталин // Логос. 2018. Т. 28. № 4. С. 27-54.

3. Джеймисон Ф. Постмодернизм, или культурная логика позднего капитализма. М.: Издательство Института Гайдара, 2019.

4. Корте Г. Введение в системный киноанализ. М.: Издательский дом НИУ ВШЭ, 2018.

5. Куренной В.А. Целлулоидный апокалипсис // Логос. 2000. № 3. С. 116-138.

6. Павлов А.В. Анализ фильма: теперь и в России // Корте Г. Введение в системный киноанализ. М.: Издательский дом НИУ ВШЭ, 2018. C. 11-24.

7. Скал Д.Дж. Книга ужаса. История хоррора в кино. СПб.: Амфора, 2009.

8. Хантер И. Бивер Лас-Вегас! Слово фаната в защиту «Шоугелз»// Логос. 2014. № 5. C. 79-96.

9. Burch, N., 2003. Embarrassing Showgirls. Film Quaterly, Vol. 56, no. 3, pp. 35-36.

10. Cass, J., 1999. SS Troopers: cybernostalgia and Paul Verhoeven's fascist flirtation. Studies in Popular Culture, Vol. 21, no. 3, pp. 51-63.

11. Crim, B., 2010. The intergalactic final solution: Nazism and genocide in Paul 
Verhoeven's Starship Troopers. Shofar: An Interdisciplinary Journal of Jewish Studies, Vol. 28, no. 4, pp. 104-115.

12. D'Amato, B. and Rimanelli, D., 2016. Dutchman's breaches. In: Barton-Fumo, M. ed., 2016. Paul Verhoeven: interviews. Jackson: University Press of Mississippi, pp. 130-140.

13. Dickinson, D., 1986. What is one to make of Robert A. Heinlein? Modern Fiction Studies, Vol. 32, no. 1, pp. 127-131.

14. Geniusas, S., 2015. Between phenomenology and hermeneutics: Paul Ricoeur's philosophy of imagination. Human Studies, Vol. 38, no. 2, pp. $223-241$.

15. Guéret, O., 2016. Interview with Paul Verhoeven. In: Barton-Fumo, M. ed., 2016. Paul Verhoeven: interviews. Jackson: University Press of Mississippi, pp. 126-129.

16. Kansteiner, W., 2017. Transnational Holocaust memory, digital culture and the end of reception studies. In: Andersen, T.S. and TörnquistPlewa, B. eds., 2017. The twentieth century in European memory: transcultural meditation and reception. Leiden: Brill, pp. 305-344.

17. Ravetto, K., 1998. Cinema, spectacle, and the unmaking of sadomasochist aesthetics. Annali d'Italinistica, Vol. 16, pp. 261-280.

18. Sammon, P., 1997. The making of Starship Troopers. New York: Boulevard Books.

19. Santesso, A., 2014. Fascism and science fiction. Science Fiction Studies, Vol. 41, no. 1, pp. 136-162.

20. Schnapp, T., 1996. Fascinating fascism. Journal of Contemporary History, Vol. 31, no. 2, pp. 235-244.

21. Starship Troopers: how to make fascism sexy. URL: https://www.youtube.com/watch? $\mathrm{v}=\mathrm{U}_{-}$ $\mathrm{sZdX} 3 \mathrm{tFFU} \& \mathrm{t}=119 \mathrm{~s}$

22. Telotte, J.P., 2000. Verhoeven, Virilio and «cinematic derealization». Film Quaterly, Vol. 53, no. 2 , pp. 30-38.

23. Telotte, J.P., 2001. Heinlein, Verhoeven, and the problem of the real: «Starship Troopers». Literature/Film Quaterly, Vol. 29, no. 3, pp. 196202.

24. Telotte, J.P., 2006. Narratives of resistance: Verhoeven's «Soldier of Orange». Film Criticism, Vol. 30, no. 3, pp. 3-16.

25. Verstraten, P., 2016. Humour and irony in Dutch post-war fiction film. Amsterdam: Amsterdam University Press.

26. Wikipedia contributors, 2017. Focus on: 100 most popular 1990s science fiction films.

\section{REFERENCES}

1. Gramci, A., 1991. Tyuremnye tetradi: v 3-kh ch. Ch. 1 [Prison notebooks: in 3 parts. Part 1]. Moskva: Politizdat. (in Russ.)

2. Groys, B., 2018. Kventin Meiyasu - eto v chistom vide Stalin [I see Quentin Meillassoux as exactly like Stalin], Logos, Vol. 28, no. 4, pp. 27-54. (in Russ.)

3. Jameson, F., 2019. Postmodernism, ili kul'turnaya logika pozdnega kapitalizma [Postmodernism, or, the cultural logic of late capitalism]. Moskva: Izdatel'stvo Instituta Gaidara. (in Russ.)

4. Korte, H., 2018. Vvedenie v sistemnyi kinoanaliz [Introduction to systematic film analysis]. Moskva: Izdatel'skii dom NIU VShE. (in Russ.)

5. Kurennoi, V.A., 2000. Tsellyuloidnyi apokalipsis [Celluloid apocalypse], Logos, no. 3, pp. 116-138. (in Russ.)

6. Pavlov, A.V., 2018. Analiz fil'ma: teper' i v Rossii [Film analysis: now in Russia]. In: Korte, H., 2018. Vvedenie v sistemnyi kinoanaliz. Moskva: Izdatel'skii dom NIU VShE, pp. 11-24. (in Russ.)

7. Skal, D.J., 2009. Kniga uzhasa. Istoriya horrora $\mathrm{v}$ kino [The monster show: a cultural history of horror]. Sankt-Peterburg: Amfora. (in Russ.)

8. Hunter, I.Q., 2014. Biver Las-Vegas! Slovo fanata V zashchitu «Showgirls» [Beaver Las Vegas! A fan's defense of Showgirls], Logos, no. 5, pp. 79-96. (in Russ.)

9. Burch, N., 2003. Embarrassing Showgirls. Film Quaterly, Vol. 56, no. 3, pp. 35-36.

10. Cass, J., 1999. SS Troopers: cybernostalgia and Paul Verhoeven's fascist flirtation. Studies in Popular Culture, Vol. 21, no. 3, pp. 51-63.

11. Crim, B., 2010. The intergalactic final solution: Nazism and genocide in Paul Verhoeven's Starship Troopers. Shofar: An Interdisciplinary Journal of Jewish Studies, Vol. 28 , no. 4, pp. 104-115.

12. D'Amato, B. and Rimanelli, D., 2016. Dutchman's breaches. In: Barton-Fumo, M. ed., 2016. Paul Verhoeven: interviews. Jackson: University Press of Mississippi, pp. 130-140.

13. Dickinson, D., 1986. What is one to make of Robert A. Heinlein? Modern Fiction Studies, Vol. 32, no. 1, pp. 127-131.

14. Geniusas, S., 2015. Between phenomenology and hermeneutics: Paul Ricoeur's philosophy of imagination. Human Studies, Vol. 38, no. 2, pp. 223-241.

15. Guéret, O., 2016. Interview with Paul Verhoeven. In: Barton-Fumo, M. ed., 2016. Paul 
Verhoeven: interviews. Jackson: University Press of Mississippi, pp. 126-129.

16. Kansteiner, W., 2017. Transnational Holocaust memory, digital culture and the end of reception studies. In: Andersen, T.S. and TörnquistPlewa, B. eds., 2017. The twentieth century in European memory: transcultural meditation and reception. Leiden: Brill, pp. 305-344.

17. Ravetto, K., 1998. Cinema, spectacle, and the unmaking of sadomasochist aesthetics. Annali d'Italinistica, Vol. 16, pp. 261-280.

18. Sammon, P., 1997. The making of Starship Troopers. New York: Boulevard Books.

19. Santesso, A., 2014. Fascism and science fiction. Science Fiction Studies, Vol. 41, no. 1, pp. 136-162.

20. Schnapp, T., 1996. Fascinating fascism. Journal of Contemporary History, Vol. 31, no. 2, pp. 235-244.
21. Starship Troopers: how to make fascism sexy. URL: https://www.youtube.com/watch?v=U_ $\mathrm{sZdX} 3 \mathrm{tFFU} \& \mathrm{t}=119 \mathrm{~s}$

22. Telotte, J.P., 2000. Verhoeven, Virilio and «cinematic derealization». Film Quaterly, Vol. 53, no. 2, pp. 30-38.

23. Telotte, J.P., 2001. Heinlein, Verhoeven, and the problem of the real: «Starship Troopers». Literature/ Film Quaterly, Vol. 29, no. 3, pp. 196-202.

24. Telotte, J.P., 2006. Narratives of resistance: Verhoeven's «Soldier of Orange». Film Criticism, Vol. 30, no. 3, pp. 3-16.

25. Verstraten, P., 2016. Humour and irony in Dutch post-war fiction film. Amsterdam: Amsterdam University Press.

26. Wikipedia contributors, 2017. Focus on: 100 most popular 1990s science fiction films.

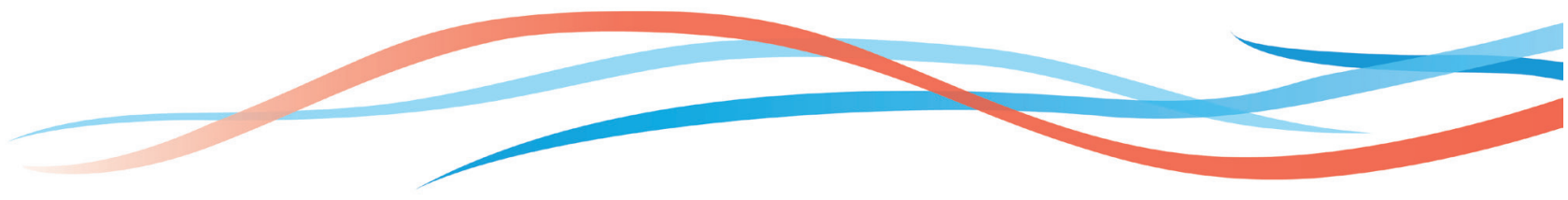

